\title{
Macrophage migration inhibitory factor in ocular fluids of patients with uveitis
}

\author{
Chikako Taguchi, Sunao Sugita, Yoshitsugu Tagawa, Jun Nishihira, Manabu Mochizuki
}

Department of Ophthalmology, Kurume University School of Medicine, Fukuoka, Japan C Taguchi

Department of Ophthalmology and Visual Science, Tokyo Medical and Dental University, Graduate School, Tokyo, Japan S Sugita

M Mochizuki

Department of Ophthalmology, Hokkaido University School of Medicine, Hokkaido, Japan Y Tagawa

The Central Research Institute, Hokkaido University School of Medicine, Hokkaido, Japan

J Nishihira

Correspondence to: Manabu Mochizuki, Department of

Ophthalmology and Visual Science, Tokyo Medical and Dental University, Graduate School, Tokyo, Japan m.manabu.oph@ med.tmd.ac.jp

Accepted for publication 27 April 2001

\begin{abstract}
Aims-To investigate the levels of macrophage migration inhibitory factor (MIF) in intraocular fluids of uveitis patients, the capacity of intraocular infiltrating lymphocytes to produce MIF, and the correlation between MIF levels in the eye and intraocular inflammatory activity.

Methods-MIF levels were measured by enzyme linked immunosorbent assay (ELISA) using (1) aqueous humour (AH) of 12 uveitis patients and eight control patients with cataract, (2) vitreous fluid of 15 uveitis patients and eight control patients with idiopathic macular hole, and (3) culture supernatants of $T$ cell clones (TCCs) established from intraocular fluids of uveitis patients. MIF expression on infiltrating cells was determined by a double staining immunofluorescence technique using a flow cytometry.

Results-Significant levels of MIF were detected from intraocular fluids of uveitis patients (4.0 (SD 3.0) $\mathrm{ng} / \mathrm{ml}$ in $\mathrm{AH}$ and 16.5 (24.7) $\mathrm{ng} / \mathrm{ml}$ in vitreous), whereas MIF levels in control groups were below the detectable levels. There was a significant correlation between MIF levels and vitreous inflammation $(29.7(30.0) \mathrm{ng} / \mathrm{ml}$ in active uveitis $v 3.3(2.6) \mathrm{ng} / \mathrm{ml}$ in inactive uveitis, $p<0.05)$. Significant levels of MIF were detected in culture supernatants of TCCs from ocular fluids of uveitis patients. MIF was expressed on infiltrating CD4+ lymphocytes from vitreous of uveitis patients.
\end{abstract}

Conclusion-Significant levels of MIF are present in intraocular fluids of patients with uveitis. Lymphocytes infiltrating in the eye are capable of producing MIF. MIF levels in vitreous fluid are correlated with vitreous inflammation activity. These data thus indicate that MIF in the eye has a significant role in the pathophysiology of ocular inflammation.

(Br f Ophthalmol 2001;85:1367-1371)

Macrophage migration inhibitory factor (MIF) was originally discovered as a $\mathrm{T}$ lymphocyte derived factor to inhibit macrophage migration. ${ }^{1}$ Recent investigations have demonstrated that MIF is a pro-inflammatory pituitary and macrophage cytokine and a critical mediator of septic shock. ${ }^{2}$ Furthermore, MIF is capable of overcoming glucocorticoid mediated inhibition of cytokines, such as tumour necrosis factor $\alpha$ (TNF $\alpha$ ), interleukin (IL)-1 $\beta$, IL-6, IL-8, and interferon $\gamma(\mathrm{IFN} \gamma) .{ }^{3}{ }^{4}$ Expression of MIF was also found in human vascular endothelial cells. $^{5}$ Nishihira ${ }^{6}$ cloned rat MIF cDNA and identified nucleotide sequence of the cDNA. They demonstrated that MIF mRNA was expressed in a wide variety of organs, such as the brain, kidney, and liver. ${ }^{6}$

In the eye, MIF is constitutively expressed in human corneal epithelial and endothelial cells, ${ }^{7}$ iris, ciliary epithelium, and retina of the rat. ${ }^{89}$ Although the function of MIF in the eye has not been well studied, Apte et al demonstrated that MIF shared more than $90 \%$ homology with a factor in the aqueous humour $(\mathrm{AH})$ which inhibited natural killer (NK) cell mediated lysis of corneal endothelial cells. ${ }^{10}$ The NK cell inhibitory effects of AH were neutralised by anti-MIF antibody. Moreover, recombinant MIF (rMIF) induced a similar inhibition on NK cell activity. These findings suggest that MIF is capable of inhibiting at least one immune effector element, NK cells, and thereby contributing in immune privilege in the eye.

In patients with uveitis, serum levels of MIF were significantly higher than those in healthy control. ${ }^{11}$ Moreover, in patients with Behçet's disease the serum MIF levels in the exacerbation stage were significantly higher than those in the convalescent stage. These observations suggest that the MIF level in the sera is associated with ocular inflammation. However, no studies have investigated MIF in the local site of ocular inflammation. The present study was, therefore, aimed at measuring MIF concentrations in ocular fluids of patients with uveitis and the capacity of infiltrating lymphocytes to produce MIF.

\section{Materials and methods}

SUBJECTS

Twelve patients with various types of uveitis were used to collect AH (Table 1). The intensity of anterior uveitis was graded according to the scoring system of Hogan et al. ${ }^{12}$ Eight patients (three males and five females, mean age 56 years old) with cataract who had no history of intraocular inflammation were used as a control group. The AH samples $(100 \mu \mathrm{l})$ from the uveitis patients were collected using a 29 gauge needle through the peripheral cornea after disinfection and local anaesthesia. The AH samples $(100 \mu \mathrm{l})$ from the cataract patients were collected during cataract surgery. Immediately after sampling, $\mathrm{AH}$ was centrifuged $3000 \mathrm{rpm}$ for 5 minutes and the supernatant was collected and frozen at $-80^{\circ} \mathrm{C}$ until use.

The vitreous fluid was obtained from 15 patients (16 samples) with various types of uveitis (Table 2) during vitreous surgery to treat epiretinal membrane, retinal detachment, 
or persistent vitreous opacities. Among the 15 patients (16 samples), eight samples were taken at the time of active vitreous inflammation more than grade 1 according to the grading scale of Nussenblatt et al..$^{13}$ The other eight samples were taken at the time of no active vitreous inflammation during vitrectomy in order to remove epiretinal membrane, fibrovascular membrane, and persistent vitreous haemorrhage. The vitreous fluids of eight patients with idiopathic macular hole (three males and five females, mean age 58.9 (SD 5.2) years old) was collected during vitreous surgery and used as a control group. Immediately after sampling, vitreous was centrifuged $10000 \mathrm{rpm}$ for 10 minutes and the supernatant was collected and frozen at $-80^{\circ} \mathrm{C}$ until use.

Twelve other patients with uveitis (two patients each of Behçet's disease, VogtKoyanagi-Harada (VKH) disease, and human $\mathrm{T}$ cell lymphotropic virus type I (HTLV-I) uveitis; one patient each of acute anterior uveitis, acute retinal necrosis syndrome, cytomegalovirus retinitis, and toxocariasis) were subjected to established $\mathrm{T}$ cell clones (TCCs) from infiltrating cells in $\mathrm{AH}$ or vitreous fluid. Two patients (Behçet's disease and VKH disease) were also subjected to established TCCs from peripheral blood mononuclear cells (PBMC). Each patient had active inflammation in the anterior chamber or vitreous at the time of sampling. PBMC of two healthy donors were used to establish PBMC TCCs (PBMC-TCCs) as controls.

This study was performed according to the tenets of the Declaration of Helsinki. Informed consent was obtained from each patient before collecting $\mathrm{AH}$ and vitreous fluid.

ESTABLISHMENT OF TCCS

TCCs were established cells by limiting dilution methods described previously. ${ }^{14}$ Briefly, cells from $\mathrm{AH}$, vitreous fluid, and PBMC were placed at a concentration of one cell per well in 96 well $\mathrm{U}$ bottom tissue culture plates (Falcon, Lincoln Park, NJ, USA) in the presence of $2 \times 10^{5}$ irradiated (50 Gy) allogeneic PBMC obtained from healthy volunteers (negative for HTLV-I, hepatitis virus type A, $\mathrm{B}$, and $\mathrm{C}$ ) as the feeder cells. The medium used for the culture was RPMI-1640 medium (Gibco Laboratories, Grand Island, NY, USA) supplemented with $100 \mathrm{U} / \mathrm{ml}$ penicillin $\mathrm{G}$, $50 \mu \mathrm{g} / \mathrm{ml}$ streptomycin, $10 \%$ heat inactivated fetal calf serum (FCS) (Bioserum, Parkville, Victoria, Australia), and $100 \mathrm{U} / \mathrm{ml}$ human recombinant IL-2 (rIL-2) (Shionogi Pharmaceutical, Osaka, Japan). The plated cells were incubated in humidified 5\% carbon dioxide in air at $37^{\circ} \mathrm{C}$. The feeder cells were added to each well along with $100 \mathrm{U} / \mathrm{ml}$ rIL-2 every 7 days until an outgrowth of cells was observed. The proliferating cells were maintained with the feeder cells and rIL-2 in 24 well tissue culture plates (Falcon) and used for further studies. The TCCs were washed three times with RPMI 1640 medium, then cultured at $5 \times 10^{5}$ cells/ml in RPMI 1640 medium supplemented with $10 \%$ FCS in 48 well tissue culture plates
(Falcon) for 22 hours. Cell free culture supernatant of TCC were collected and stored at $-80^{\circ} \mathrm{C}$ until use for MIF assay.

\section{MEASUREMENT OF MIF}

The concentrations of MIF in $\mathrm{AH}$, vitreous fluid, and supernatant of TCCs were measured by enzyme linked immunosorbent assay (ELISA) as described elsewhere. ${ }^{11}$ Briefly, the anti-human MIF antibody was added to each well of a 96 well microtitre plate and left for 1 hour at room temperature. All wells were filled with phosphate buffered saline containing $1 \%$ bovine serum albumin for blocking and left for 1 hour at room temperature. Samples were added into individual wells in a duplicate manner and incubated for 1 hour at room temperature. After the plate was washed three times, 50 $\mu \mathrm{l}$ biotin conjugated anti-human MIF antibody (IgG fraction) was added to each well. The polyclonal anti-human MIF antibody was generated by immunising New Zealand white rabbits with purified recombinant human MIF. The IgG fraction $(4 \mathrm{mg} / \mathrm{ml})$ was prepared using Protein A Sepharose (Pharmacia, Uppsala, Sweden) according to the manufacturer's protocol. After incubation for 1 hour, streptavidin-horseradish peroxidase conjugated goat anti-rabbit IgG antibody (Bio-Rad, Hercules, CA, USA) was added to each well and incubated for 1 hour. Fifty $\mu$ l of substrate containing $o$-phenylenediamine (Wako, Osaka, Japan) and hydrogen peroxide (Wako) in citrate phosphate buffer ( $\mathrm{pH}$ 5.0) was added to each well. After incubate for 20 minutes, the reaction was stopped with sulphuric acid. The absorbance at $492 \mathrm{~nm}$ was measured using an ELISA plate reader. The lower limit of MIF detection by this method was $1 \mathrm{ng} / \mathrm{ml}$.

DETECTION OF MIF EXPRESSION BY FLOW CYTOMETRY

The expression of MIF was examined on the infiltrating cells in the vitreous of patients with sarcoidosis by double colour immunofluorescence technique. Immediately after sampling, the vitreous was centrifuged at $10000 \mathrm{rpm}$ for 10 minutes. Infiltrating cells were fixed in $1 \mathrm{ml}$ phosphate buffered saline (PBS) with 4\% formaldehyde and permeabilised by saponin based permeabilised medium (saponin buffer). The cells were incubated at $4^{\circ} \mathrm{C}$ for 30 minutes with anti-human MIF monoclonal antibody (3H2F; $1 \mu \mathrm{g} / \mathrm{ml})$, and stained surface marker of CD4 with PE conjugated mouse monoclonal antibody (NU-Th/i; Nichirei, Tokyo, Japan). After washing with saponin buffer, FITC conjugated goat anti-mouse IgG (Cappel; ICN Pharmaceuticals, Inc, Aurora, OH, USA) was added at $4^{\circ} \mathrm{C}$ for 30 minutes. The samples were performed by double colour fluorescence flow cytometry using FACS Caliber (Becton Dickinson Immune-cytometry Systems, San Jose, CA, USA). As well as TCCs established from aqueous humour with active uveitis in sarcoidosis were also examined by the same flow cytometry technique. In this assay, we used FITC labelled antibodies as follow; CD4 (NU-Th/i; Nichirei), CD25 (IL-2Ra), CD95 (Fas/UB2; MBL, Nagoya, Japan). 
STATISTICAL ANALYSIS

Statistical analysis was performed using MannWhitney $\mathrm{U}$ test. The difference between the two groups compared was determined to be statistically significant when the $\mathrm{p}$ value was smaller than 0.05 .

Table 1 MIF concentrations in the aqueous humour

\begin{tabular}{|c|c|c|c|c|c|}
\hline \multirow[b]{2}{*}{ Patient } & \multirow{2}{*}{$\begin{array}{l}\text { Age, sex } \\
\text { (years) }\end{array}$} & \multirow[b]{2}{*}{ Disease } & \multicolumn{2}{|l|}{ Uveitis } & \multirow{2}{*}{$\begin{array}{l}\text { MIF concentrations } \\
(\mathrm{ng} / \mathrm{ml})\end{array}$} \\
\hline & & & Anatomical type & Grade & \\
\hline 1 & $26, M$ & Behçet's diease & panuveitis & 4 & 10.6 \\
\hline 2 & $27, M$ & VKH disease & panuveitis & 3 & 2 \\
\hline 3 & $47, \mathrm{~F}$ & VKH disease & panuveitis & 2 & 4.2 \\
\hline 4 & $52, \mathrm{~F}$ & VKH disease & panuveitis & 2 & 2.2 \\
\hline 5 & $41, \mathrm{M}$ & Sarcoidosis & panuveitis & 2 & 1.9 \\
\hline 6 & $60, \mathrm{~F}$ & Sarcoidosis & panuveitis & 3 & 1.8 \\
\hline 7 & $67, M$ & Acute anterior uveitis & anterior uveitis & 4 & 1.6 \\
\hline 8 & $53, \mathrm{~F}$ & HTLV-I uveitis & panuveitis & 2 & 4.1 \\
\hline 9 & $55, \mathrm{~F}$ & ARNS & panuveitis & 4 & 4.1 \\
\hline 10 & $47, \mathrm{M}$ & ARNS & panuveitis & 4 & 9.6 \\
\hline 11 & $45, \mathrm{M}$ & Toxocariasis & panuveitis & 0 & 2.2 \\
\hline 12 & $58, M$ & Toxocariasis & panuveitis & 0 & $\begin{array}{l}3.6 \\
4.0(3.0)^{\star}\end{array}$ \\
\hline
\end{tabular}

${ }^{\star} \mathrm{p}<0.005$, compared with controls (Mann-Whitney U test).

$\mathrm{VKH}=$ Vogt-Koyanagi-Harada; HTLV-I = human $\mathrm{T}$ cell lymphotropic virus type I; ARNS = acute retinal necrosis syndrome.

Table 2 MIF concentrations in the vitreous fluid

\begin{tabular}{llllll}
\hline Patient & $\begin{array}{c}\text { Age, sex } \\
\text { (years) }\end{array}$ & Disease & Vitreous inflammation & $\begin{array}{l}\text { MIF concentrations } \\
(\text { ng/ml })\end{array}$ \\
\hline 13 & $39, \mathrm{M}$ & Behçet't diease & Active & grade 4 & 30.41 \\
14 & $47, \mathrm{M}$ & HTLV-I uveitis & Active & grade 2 & 13.06 \\
9 & $55, \mathrm{M}$ & ARNS & Active & grade 3 & 93.02 \\
15 & $55, \mathrm{~F}$ & ARNS & Active & grade 3 & 25.05 \\
10 & $46, \mathrm{M}$ & CMV retinitis & Active & grade 2 & 20.79 \\
16 & $78, \mathrm{~F}$ & CMV retinitis & Active & grade 2 & 2.97 \\
11 & $45, \mathrm{M}$ & Toxocariasis & Active & grade 3 & 50.35 \\
12 & $58, \mathrm{M}$ & Toxocariasis & Active & grade 1 & 1.91 \\
& & & & & $29.7(30.0) \dagger \ddagger$ \\
17 & $24, \mathrm{~F}$ & Behçet's diease & Inactive & grade 0 & 2.31 \\
18 & $26, \mathrm{~F}$ & Behçet's diease & Inactive & grade 0 & 4.28 \\
19 & $61, \mathrm{~F}$ & Sarcoidosis & Inactive & grade 0 & 5.66 \\
20 & $62, \mathrm{~F}$ & Sarcoidosis & Inactive & grade 0 & $<1$ \\
21 & $67, \mathrm{M}$ & Sympathetic ophthalmia & Inactive & grade 0 & 4.35 \\
22 & $55, \mathrm{M}$ & Sympathetic ophthalmia & Inactive & grade 0 & $<1$ \\
23 & $66, \mathrm{~F}$ & HTLV-I uveitis & Inactive & grade 0 & 2.65 \\
15 & $55, \mathrm{~F}$ & ARNS & Inactive & grade 0 & 7.5 \\
& & & & & $3.3(2.6)^{\star}$ \\
& & & & & $16.5(24.7) \dagger$ \\
\hline
\end{tabular}

${ }^{\star} \mathrm{p}<0.005,+\mathrm{p}<0.0005$, compared with controls (Mann-Whitney U test).

$\neq \mathrm{p}<0.05$, compared with inactive uveitis (Mann-Whitney U test).

HTLV-I = human $\mathrm{T}$ cell lymphotropic virus type I; ARNS = acute retinal necrosis syndrome; $\mathrm{CMV}=$ cytomegalovirus

Table 3 MIF production by $T$ cell clones

\begin{tabular}{llll}
\hline Disease & $\begin{array}{l}\text { Source of } \\
\text { TCC }\end{array}$ & $\begin{array}{l}\text { Number of } \\
\text { TCCs }\end{array}$ & MIF concentrations $(\mathrm{ng} / \mathrm{ml})$ \\
\hline Healthy donor & PBMC & 13 & $0.3(0.8)$ \\
Behçet's disease & PBMC & 8 & $0.2(0.6)$ \\
VKH disease & PBMC & 8 & $<1$ \\
& & & $0.1(0.4)$ \\
Behçet's disease & AH & 7 & $10.6(18.2) \dagger$ \\
VKH disease & AH & 7 & $2.7(2.7)^{\star}$ \\
Sarcoidosis & AH & 7 & $1.3(2.8)$ \\
Acute anterior uveitis & AH & 7 & $5.5(7.0)^{\star}$ \\
HTLV-I uveitis & AH & 7 & $8.2(3.1)^{\ddagger}$ \\
& & & $5.6(9.1)^{\dagger}$ \\
& & & $2.7(2.6)^{\star}$ \\
Acute retinal necrosis syndrome & Vitreous & 7 & $0.6(1.6)$ \\
CMV retinitis & Vitreous & 7 & $3.0(1.6) \dagger$ \\
Toxocariasis & Vitreous & 7 & $2.1(2.2)^{\star}$ \\
& & &
\end{tabular}

$\ddagger \mathrm{p}<0.0005, \dagger<0.005,{ }^{\star}<0.05$, compared with healthy donor's PBMC (Mann-Whitney U test). VKH = Vogt-Koyanagi-Harada; HTLV-I uveitis = human T cell lymphotropic virus type I; ARNS $=$ acute retinal necrosis syndrome; $\mathrm{CMV}=$ cytomegalovirus.

\section{Results}

MIF CONCENTRATIONS IN AH OF PATIENTS WITH UVEITIS

The MIF concentrations in AH of control patients with cataract were below the detectable levels $(<1 \mathrm{ng} / \mathrm{ml})(\mathrm{n}=8)$. In contrast, the MIF concentrations in $\mathrm{AH}$ of active uveitis were mean 4.0 (SD 3.0) $\mathrm{ng} / \mathrm{ml}(\mathrm{n}=12)$ (Table 1). The difference between the two groups was statistically significant $(\mathrm{p}<0.05)$.

MIF CONCENTRATIONS IN THE VITREOUS FLUID OF UVEITIS PATIENTS

MIF concentrations is the vitreous fluid of all control patients with macular hole were below the detectable levels $(<1 \mathrm{ng} / \mathrm{ml})(\mathrm{n}=8)$. MIF concentrations in the vitreous fluid in patients with uveitis were 16.5 (24.7) $\mathrm{ng} / \mathrm{ml}$ (Table 2). The difference between the two groups was statistically significant $(\mathrm{p}<0.0005)$.

CORRELATION BETWEEN THE VITREOUS MIF CONCENTRATIONS AND THE ACTIVITY OF VITREOUS INFLAMMATION

Among of uveitis patients, MIF in the vitreous of patients with active vitreous inflammation (29.7 (30.0) $\mathrm{ng} / \mathrm{ml}, \mathrm{n}=8$ ) was significantly higher than that of patients with inactive vitreous inflammation (3.3 (2.6) $\mathrm{ng} / \mathrm{ml}, \mathrm{n}=8$ ) $(\mathrm{p}<0.05)$ (Table 2).

MIF PRODUCTION BY TCCS ESTABLISHED FROM OCULAR FLUID

MIF concentrations in the culture supernatant of TCCs established from PBMC of healthy donors, Behçet's disease, and VKH disease were $0.3(0.8) \mathrm{ng} / \mathrm{ml}, 0.2(0.6) \mathrm{ng} / \mathrm{ml}$, and below detectable levels, respectively (Table 3 ). There was no significant difference among the three groups. In contrast, significant levels of MIF were detected in the culture supernatant of TCCs established from intraocular infiltrating cells of various entities of uveitis (Table 3). The mean MIF concentrations in the culture supernatant of AH-TCCs was 5.6 (9.1) ng/ml, and that of vitreous TCCs was $2.1(2.2) \mathrm{ng} / \mathrm{ml}$ (Table 3). A statistical significance in the MIF concentrations was recorded between $\mathrm{AH}$ TCCs from uveitis patients and PBMC-TCCs from healthy donors, and also between vitreous TCCs from uveitis patients and PBMC-TCCs from healthy donors.

DETECTION OF MIF ON OCULAR INFILTRATING CELLS AND TCCS

A double staining immunofluoresence method using flow cytometry detected MIF expression on CD4 positive TCC established from the vitreous of a patient with sarcoidosis (Fig 1A). Ninety four per cent of the cells were double positive for MIF and CD4 (Fig 1A). The cells also expressed on CD25, CD90 (Fas) and IFN- $\gamma$ (Fig 1B, C, D). The population of cells double positive for MIF and CD25, MIF and CD95, MIF and IFN $\gamma$ were $94 \%, 96 \%$, and $82 \%$, respectively (Fig $2 \mathrm{~B}-\mathrm{D}$ ). In addition, infiltrating cells freshly obtained from the vitreous of another patient with sarcoidosis were double positive for CD4 and MIF (Fig 2). 


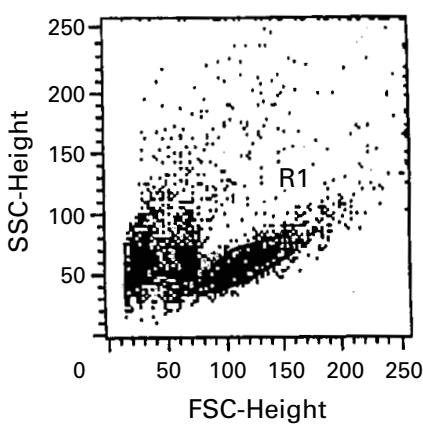

Figure 1 MIF expression in $T$ cell clones. $T$ cell clones $\left(1 \times 10^{6}\right.$ cells $)$ were fixed in 1 $\mathrm{ml} P B S$ with $4 \%$ formaldehyde and permeabilised by saponin buffer. These cells were incubated at $4^{\circ} \mathrm{C}$ for 30 minutes with anti-human MIF monoclonal antibody (clone $3 \mathrm{H} 2 \mathrm{~F} ; 1 \mathrm{\mu g} / \mathrm{ml}$ ) and FITC labelled antibodies as follows: CD4, CD25, CD95 (Fas), IFN- $\gamma$. After washing with saponin buffer, PE conjugated goat anti-mouse IgG was added at $4^{\circ} \mathrm{C}$ for 30 minutes. The samples underwent double colour fluorescence flow cytometry. The stained cell used was a CD4+ T cell clone established from ocular fluid (S3-14 established from patient with sarcoidosis). (A) indicates CD4-FITC/MIF-PE; (B) indicates CD25-FITC/MIF-PE; (C) indicates CD95-FITC/MIF-PE; (D) indicates $I F N-\gamma-F I T C / M I F-P E$.
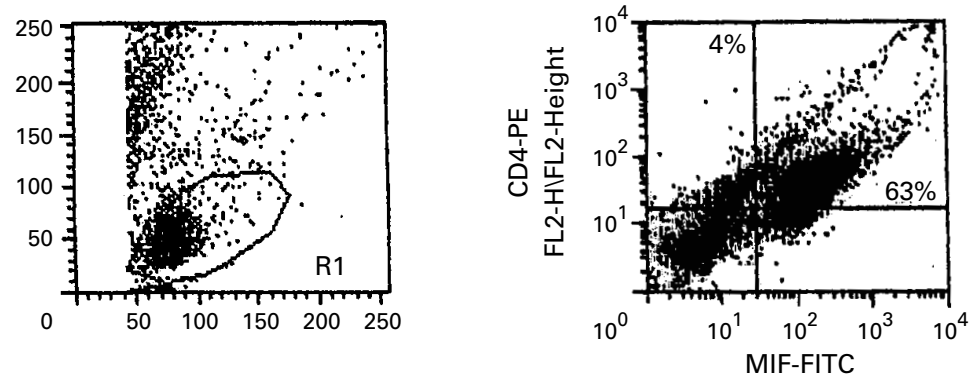

Figure 2 MIF expression in ocular infiltrating cells. The expression of MIF was infiltrating cells in the vitreous of patients with sarcoidosis with active uveitis by flow cytometry. These cells incubated at $4^{\circ} \mathrm{C}$ for 30 minutes with anti-human MIF monoclonal antibody (clone $3 \mathrm{H} 2 \mathrm{~F} ; 1 \mu \mathrm{g} / \mathrm{ml}$ ) and PE labelled CD4 antibody. After washing with saponin buffer, FITC conjugated goat anti-mouse IgG was added. The samples underwent double colour fluorescence flow cytometry.
A

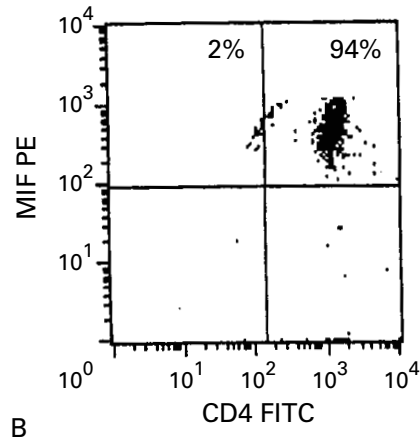

C
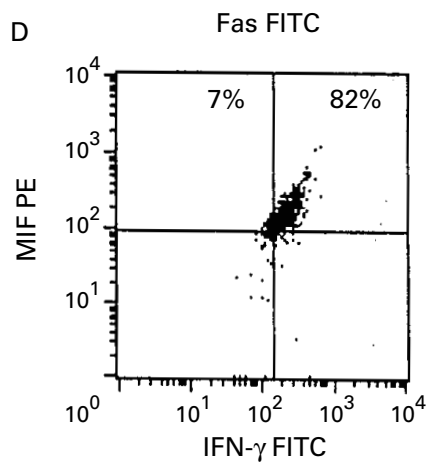

The population of cells double positive for MIF and CD4 was $63.0 \%$.

\section{Discussion}

The present study demonstrated for the first time that $\mathrm{AH}$ and vitreous fluid of patients with uveitis contained significant levels of MIF and the MIF levels in the intraocular fluids correlated with activity of intraocular inflammation. The mean MIF levels in $\mathrm{AH}$ and vitreous fluids in active uveitis were $4.0(3.0) \mathrm{ng} / \mathrm{ml}$ and 29.7 (30.0) $\mathrm{ng} / \mathrm{ml}$, respectively. The reason why MIF levels in $\mathrm{AH}$ were much lower than those in vitreous fluid is not known, but it could be attributed to a high rate of the aqueous outflow via the trabecular meshwork compared with a low turnover rate of the vitreous. In a previous study by Kitaichi et $a l^{11}$ high MIF levels were detected in the sera of uveitis patients - that is, 60.4 (9.0) $\mathrm{ng} / \mathrm{ml}$ in Behçet's disease, 16.5 (2.9) $\mathrm{ng} / \mathrm{ml}$ in VKH disease, 27.7 (5.1) $\mathrm{ng} / \mathrm{ml}$ in sarcoidosis, and $5.4(0.04) \mathrm{ng} / \mathrm{ml}$ in healthy donors. The MIF level in the vitreous measured in our study was similar level to that MIF levels in the sera reported in the previous study. Because it is well known that the blood-ocular barrier is disrupted when intraocular inflammation occurs, the data described above might indicate a possibility that MIF detected in the eye might passively enter from the peripheral circulation into the eye. Therefore, we performed two independent experiments to test whether MIF in the eye is, at least in part, produced and released by intraocular infiltrating cells. To investigate the capacity of local inflammation cells to produce MIF, we established TCCs from intraocular infiltrating cells and tested their capacity to produce MIF. MIF levels in the cultured supernatant of TCCs established from intraocular infiltrating cells in $\mathrm{AH}$ and vitreous fluid of uveitis patients was 5.6 (9.1) $\mathrm{ng} / \mathrm{ml}$ and 2.1 (2.2) $\mathrm{ng} / \mathrm{ml}$, respectively. These data indicate that intraocular infiltrating $\mathrm{T}$ lymphocytes have a capacity to produce and release significant levels of MIF. This notion was further supported by another experiment using a double staining immunofluoresence technique-namely, CD4+ $\mathrm{T}$ lymphocytes (ocular infiltrating cells and TCCs) in the ocular fluids of uveitis patients expressed MIF (Figs 1 and 2). Therefore, MIF detected in AH and vitreous fluid in the present study was, at least in part, produced by $\mathrm{T}$ lymphocytes infiltrating in the eye. However, MIF production by PBMC of uveitis patients appears to be very low as demonstrated by extremely low or no production of MIF by TCCs from PBMC of patients with Behçet's disease and VKH disease. It noteworthy that TCCs established from the ocular infiltrating cells of same patients produced much higher levels of MIF than the PBMC-TCCs (Table 3). These data thus suggest that intraocular infiltrating cells are upregulated much more actively than PBMC in terms of the capacity to produce MIF.

As for the relation between MIF and pathophysiology, the present study showed a significant correlation between MIF levels in the vitreous fluid and the activity of vitreous inflammation. This suggests a significant role 
of MIF in the pathophysiology of intraocular inflammation. The subjects of the present study were heterogeneous, and included a few patients in each disease entity, because informed consent was difficult to obtain from uveitis patients for sampling $\mathrm{AH}$ and vitreous fluid. Thus, correlation between intraocular MIF and uveitis was not analysed and this remains a subject for the further studies.

In conclusion, a significant level of MIF is present in intraocular fluid ( $\mathrm{AH}$ and vitreous fluid) of uveitis patients and the intraocular $\mathrm{MIF}$ is, at least in part, produced by infiltrating lymphocytes. The MIF levels in the eye correlate with the intensity of intraocular inflammation. These data thus suggest a significant role for MIF in the pathophysiology of intraocular inflammation.

We are grateful to Kimitaka Sagawa, Kurume University School of Medicine, for support in establishing $\mathrm{T}$ cell clones, Koich Yoshimura and Naofumi Hikita of Kurume University School of Medicine, for providing ocular fluid from patients, and Yuka Mizue of Sapporo Immunodiagnostic Laboratory, for measuring of MIF by ELISA.

1 David JR. Delayed hypersensitivity in vitro: its mediation by cell-free substances formed by lymphoid cell-antigen interaction. Proc Natl Acad Sci 1966;56:72-7.

2 Bernhagen J, Calandra T, Mitchell RA. MIF is a pituitary-derived cytokine that potentiates lethal endotoxaemia. Nature 1993;365:756-9.

3 Calandra T, Bernhagen J, Mitchell RA, et al. The macrophage is an important and previously unrecognized source of macrophage migration inhibitory factor. $\mathcal{7}$ Exp Med 1994;179:1895-902.

4 Calandra T, Bernhagen J, Mets $\mathrm{CN}$, et al. MIF as a glucocorticoid-induced modulator of cytokine production. Nature 1995;377:68-71.

5 Nisihira J, Koyama Y, Mizue Y. Identification of macrophage migration inhibitory factory (MIF) in human vascuar endothelial cells and its induction by lipopolysaccharide. Cytokine 1998;10:199-205.

6 Nishihira J. Novel pahtophysiological aspects of macrophage migration inhibitory factor. Int $\mathcal{F} \mathrm{Mol} \mathrm{Med} \mathrm{1998;2:}$ $17-28$.

7 Matsuda A, Tagawa Y, Matsuda H, et al. Identification and immnohistochemical localization of macrophage migration inhibitory factor in human cornea. FEBS Lett 1996;385: $225-8$.

8 Matsuda A, Kotake S, Tagawa Y, et al. Detection and immunolocalization of macrophage migration inhibitory factor in rat iris and ciliary epithelium. Immunol Lett 1996; 53:1-5

9 Matsuda A, Tagawa Y, Yoshida K, et al. Expression of macrophage migration inhibitory factor in rat retina and its immnohistochemical localization. F Neuroimmunol 1997; 77:85-90.

10 Apte RS, Sinha D, Mayhew E, et al. Role of macrophage migration inhibitory factor in inhibiting NK cell activity and preserving immune privilege. 7 Immunol 1998;160: and preser

11 Kitaichi N, Kotake S, Sasamoto Y, et al. Prominent increase of macrophage migration inhibitory factor in the sera of patients with uveitis. Invest Ophthalmol Vis Sci 1999;40: $247-50$

12 Hogan MJ, Kimura SJ, Thygeson P. Signs and symptoms of uveitis. 1. Anterior uveitis. Am f Ophthalmol 1959;47-II: 155-70.

13 Nussenblatt RB, Palestine AG, Chan C-C, et al. Standardization of vitreal inflammatory activity in intermediate and posterior uveitis. Ophthalmology 1985;92:467-71.

14 Sagawa K, Itoh K, Sakaguchi M, et al. Production of IL-8 and the other cytokines by $\mathrm{T}$ cell clones established from the ocular fluid of patients with Behçet's disease. Ocular Immunol Inflam 1995;3:63-71. 